\title{
Research on Short Video Marketing Path of Traditional Handicrafts
}

\author{
Xiaochen Geng ${ }^{1,3} \mathrm{Ji} \mathrm{He}^{2, *}$
}

\author{
${ }^{1}$ School of Art, Nantong University, Nantong, Jiangsu, China \\ ${ }^{2}$ School of Business Administration, Guizhou University of Finance and Economics, Guiyang, Guizhou 550025, China \\ ${ }^{3}$ Fuzhou University, Fuzhou, Fujian, China \\ *Corresponding author. Email: 732563710@qq.com
}

\begin{abstract}
This article analyzes the past marketing methods and disadvantages of traditional handicrafts through literature analysis, induction and summary, and finds that the key to solving the problem of mismatch between supply and demand in traditional sales models is to expand the sales channels of traditional handicrafts. The advantages of the short video platform such as fairer algorithms, simple and fast production, and high information density make short videos very suitable for the marketing of traditional handicrafts. Traditional craftsmen can show the artistic and aesthetic value of handicrafts by presenting the production process of traditional handicrafts in short videos, and embed the commodity purchase links in the short videos for short video marketing of handicrafts.
\end{abstract}

Keywords: handicrafts, short video, marketing path

\section{INTRODUCTION}

Traditional handicrafts, as an important carrier of folk art and culture, contain profound content such as people's life, customs, and national culture. However, in the age of industrialization, the production of traditional handicrafts is time-consuming and laborintensive, leading to higher costs than industrial products and facing the embarrassing situation of being replaced by industrial products and traditional handicrafts without successors. ${ }^{1}$ This article takes the characteristics of handicrafts and the mismatch between demand and supply caused by previous marketing methods as an entry point, and explores how to integrate them into the short video marketing path. The intention is to allow young people to be willing to inherit the craft and allow young craftsmen to obtain economic benefits from the traditional handicraft work.

*Project: 2017 Guizhou Provincial Department of Education Youth Science and Technology Talent Growth Project (Project No.: Qian Jiaohe KY [2017] 152); 2018 Guizhou University of Finance and Economics Teaching Quality and Teaching Reform Project "Research on the Cultivation of College Students' Innovation and Entrepreneurship Ability" (Project No.: 2018JGZZC67); 2017 Guizhou University of Finance and Economics introduced the talent research project "Research on the Core Issues of Guizhou Promoting Supply-side Reform".

Chen Wenyuan, Li Xiaoyan, On the Minority's Traditional Handicraft Industry in Heritage Village: Take Silver Survey of Xinhua Village in Yunnan Heqing as an Example [J]. Guizhou Ethnic Studies, 2017(08), p193-197.

\section{THE DISADVANTAGES OF TRADITIONAL MARKETING METHODS FOR TRADITIONAL HANDICRAFTS}

Traditional handicrafts are exquisite handcrafts made by hand. While they are practical, they are more artistic, creative and aesthetic than industrial products. The production of traditional handicrafts is largely dependent on the creation of craftsmen. The mastery of production techniques and processes determines the appearance, quality, artistry, and appreciation of handicrafts. Handcraft skills are generally passed down from generation to generation in the form of master and apprentice, and production experience is accumulated by on-site observation and actual operation. Therefore, traditional handicrafts cannot be mass-produced due to manual production, resulting in high production costs, low yields and high prices.

\section{A. Traditional handicrafts sales modes in the past and their disadvantages}

Traditional handicrafts sales modes in the past include direct visits, unified purchases, self-operated websites, traditional e-commerce platforms and WeChat-business channel, etc.:

- The direct visit method refers to a sales mode in which potential consumers go directly to the place where traditional handicrafts are produced, and generate purchase intentions by observing the production process of handicrafts. This mode 
can directly show consumers the aesthetic cultural connotation, manufacturing techniques, materials, etc. of traditional handicrafts. Consumers can intuitively feel the difference between traditional handicrafts and industrial products and generate purchase intentions.

- The unified purchases method refers to the unified purchases and unified sales of traditional handicrafts by village-run and town-run enterprises. Craftsmen can regularly sell their handicrafts through this mode. However, the purchase price of enterprises is generally much lower than the actual selling price of handicrafts, and the profit margin of craftsmen is greatly squeezed, which is not conducive to the creative enthusiasm of craftsmen.

- Self-operated websites refer to the establishment of websites by handicraft manufacturers to sell handicrafts. This model is a corporate website established on the basis of unified corporate acquisition. Therefore, this mode requires a lot of manpower and material resources to manage the websites in addition to the reduction of profit margins for craftsmen, and the majority of visitors to the website are regular customers and new customers. The number of new visits is not guaranteed.

- Traditional e-commerce platforms refer to traditional e-commerce platforms such as Taobao and JD. The sales of traditional handicrafts on traditional e-commerce platforms are not optimistic. For example, when searching for "individual old tinware" on Taobao, using "sales" as the filter criteria, there are only 5 tinwares been sold with the largest sales volume. The reasons for the poor sales of traditional handicrafts on traditional e-commerce platforms are that customers do not know much about traditional handicrafts, customers are unwilling to pay a high price for the cultural aesthetic connotation of traditional handicrafts, and it is difficult for customers to judge the quality of handicrafts.

- WeChat-business channel: the biggest drawback of selling traditional handicrafts in the WeChatbusiness channel is that the customers in the WeChat-business channel are generally introduced by relatives and acquaintances. WeChat is an instant messaging product, and the information dissemination is mainly based on the information dissemination between friends, which determines that it is difficult for the WeChat-business channel to expand new customers.

\section{B. The traditional sales modes lack mismatch between supply and demand}

Through the above analysis, it can be found that in the past, traditional handicraft sales modes were difficult to match the supply and demand of traditional handicrafts. Traditional handicrafts are in demand in the market, but those who need to buy traditional handicrafts do not have suitable purchase channels, resulting in a mismatch between the supply and demand of traditional handicrafts. There is no effective way for traditional handicrafts to reach their buyers, and people who need to buy traditional handicrafts cannot find a suitable purchase channel. To match the supply and demand of traditional handicrafts, the publicity audience of traditional handicrafts must be expanded.

\section{The key to expanding sales channels}

To expand the sales channels of traditional handicrafts, the most important thing is to let more people understand traditional handicrafts and their folk culture and artistic value. Potential customers need to intuitively see the production process of traditional handicrafts and understand the cultural and aesthetic connotations of traditional handicrafts, so that they will pay higher prices than industrial products to buy traditional handicrafts. For example, customers see that Suzhou embroidery craftsmen divide the embroidery thread as thick as the hair into finer threads, hide thousands of thread ends in the embroidery, and then use various stitching methods on both the front and back of the embroidery. By understanding the production process of double-sided embroidery, customers will better understand the aesthetic and artistic value of double-sided embroidery, are more likely to have the motivation to buy double-sided embroidery, and are more willing to pay higher prices than industrial products. Therefore, the key to expanding the marketing channels of traditional handicrafts is to show the production process of traditional handicrafts and the aesthetic and artistic value contained in them to more audiences.

\section{SHORT VIDEO MARKETING PATH FOR TRADITIONAL HANDICRAFTS}

\section{A. Short video marketing advantage}

Short video refers to the share videos, usually videos that last from a few seconds to a few minutes. Short video marketing refers to the use of short videos as a medium to sell products on short video platforms. Just like Kuaishou's ad slogan: "Let the people in the city taste the freshness of the world, and the people in the village earn money across the country." Short video users can use short videos as a medium for advertising. Short videos have natural marketing value. 
The advantage of short video marketing compared with previous online marketing lies in the fairer algorithm of the short video platform. First of all, the algorithm push scheme of the short video platform enables the short videos produced by ordinary short video users to have more audiences. Traditional ecommerce platforms push product display according to price, sales volume, etc., while ordinary merchants' products are placed on traditional e-commerce platforms, and there is almost no opportunity to push them to potential customers. The algorithm of the short video platform is more fair. This fairer algorithm will give the short videos of ordinary short video users a traffic pool, which ensures that the short videos of ordinary users will also be pushed to a certain number of strangers. For ordinary short video users, there is a fairer platform to present themselves. Secondly, short video production is simple and fast. It does not require copywriting, text editing, etc., and does not require too much video shooting and editing skills. Ordinary people can shoot and edit a short video with a mobile phone to deliver the content they want to express. In addition, short video has a high information density, which can contain a large amount of information within ten seconds to a few minutes. It is more dense than text, pictures and other forms, and can transmit more information in a shorter time. There is no need to pay too much information search cost, which is also a factor in the explosive growth of short videos.

\section{B. Short video marketing path for traditional handicrafts}

Traditional handicrafts contain cultural and artistic value. This feature makes it necessary for consumers to understand the difference between traditional handicrafts and industrial products in the sale of traditional handicrafts. Craftsmen can use short videos to market traditional handicrafts and open up new channels for the sale of traditional handicrafts.

1) Using short videos to present the production process of traditional handicrafts: Traditional craftsmen can record the production process of traditional handicrafts, national cultural life, etc. by shooting short videos and put them on the short video platforms. Through the short video platform, short videos are pushed to different short video users, so that more people can understand traditional handicrafts, understand the production process of traditional handicrafts, national cultural life, etc., achieving the purpose of traditional handicraft marketing. As shown in the picture, a short video on Douyin can fully show the production process of tin crafts. The production process of tin crafts is divided into tin melting, stone fan casting, tin pressing, proofing and cutting, sheet metal, foiling, polishing ${ }^{2}$, etc. A 57-second short video is shown in "Fig. 1", "Fig. 2" and "Fig. 3", showing the entire process of tin melting, stone casting, and tin pressing, which allows viewers to intuitively understand the entire production process of tin from raw materials to tin plates. Short videos can show potential customers intuitively and completely the production process of traditional handicrafts in the shortest time.

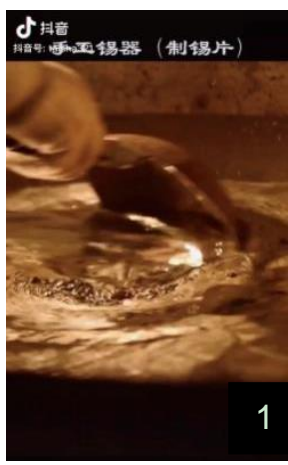

Fig. 1. Melting tin.

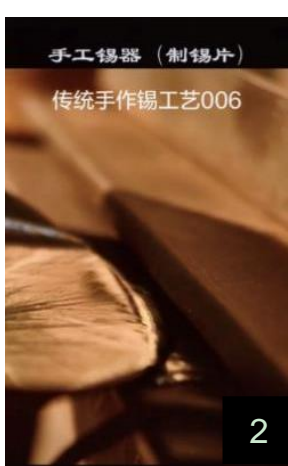

${ }^{\text {a. }}$ Image source: Douyin

Fig. 2. Casting in stone model.

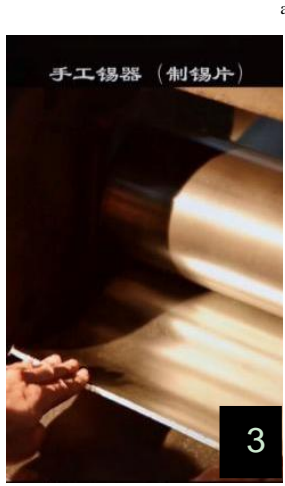

Fig. 3. Pressing tin flake.

Image source: Douyin

2 Geng Xiaochen, Study on the Art of Chinese Tin Products [D]. Soochow University, 2013, p76. 
2) Embedding commodity purchase links in short videos: If the potential customers see the short videos, by watching the short videos, after understanding the production process of traditional handicrafts and the cultural and aesthetic connotations, they can click on the product purchase links to purchase the products directly if they want to buy the handicrafts. Embedding product purchase links in short videos can immediately allow customers to place orders when potential customers are most motivated to purchase, increasing the sales of handicrafts.

\section{Advantages of short video marketing for traditional handicrafts}

Short video marketing of traditional handicrafts has the following advantages: First, it can expand the audience of traditional handicrafts. The fair algorithm of the short video platforms can push short video advertisements of traditional handicrafts to more audiences, so that more people can understand traditional handicrafts and increase the number of potential customers. Short video users who like traditional handicrafts can also achieve the purpose of expanding the marketing audience of traditional handicrafts by forwarding their favorite short videos to other users through the short video platforms. Second, it can more intuitively show the folk culture, craft characteristics and technological process of traditional handicrafts. The key to the marketing of traditional handicrafts is to present the national cultural connotation and artistic beauty of the traditional handicrafts to consumers, so that consumers are willing to pay higher prices than industrial products for the artistic and cultural beauty of traditional handicrafts. The form of short videos can show the technological process and national cultural value of traditional handicrafts to consumers at the lowest transaction cost (including time cost and space cost, etc.), and achieve the purpose of marketing traditional handicrafts. Third, the threshold of short video marketing is low, and ordinary craftsmen can also operate on the platforms. Short video marketing has a low threshold, does not require much professional knowledge and skills, does not require knowledge such as copywriting and composition, and does not require professional shooting equipment. It takes very little time to achieve the purpose of promoting traditional handicrafts, which is very suitable for ordinary craftsmen to conduct handicraft marketing.

\section{CONCLUSION}

Through the analysis of traditional handicrafts and their sales characteristics, it is found that the key to expanding the sales of traditional handicrafts is to export the cultural connotation and artistic beauty of traditional handicrafts to consumers, so that consumers can accept the artistic and cultural beauty of traditional handicrafts, and pay slightly higher prices than industrial products; secondly, it is necessary to expand the marketing audience of traditional handicrafts. Due to the marketing value of the short videos and the platforms, the algorithm of the short video platforms, the simple and fast production of short videos, and the high density of short video information, short videos are very suitable for handicraftsmen to market traditional handicrafts. Through short video marketing, the inherent folk culture and artistic beauty of traditional handicrafts can be presented to consumers while expanding the marketing audience, and the path of commodity purchase links can be embedded in the short video for the marketing of traditional handicrafts.

\section{References}

[1] Liu Yiqing, The Aesthetic Meaning of Handicraft [J]. DongYue Tribune, 2020(03), p121-130. (in Chinese)

[2] Li Dan, Yu Yunzheng, Zhang Lijun, Digital Communication of Traditional Handicrafts in the Era of New Media [J]. View on Publication, 2019(01), p88-90. (in Chinese)

[3] Wang Xiao, Traditional Handcrafts Reproduction Study [D]. Xi'an Academy of Fine Arts, 2016, p26. (in Chinese)

[4] Chen Wenyuan, Li Xiaoyan, On the Minority' s Traditional Handicraft Industry in Heritage Village: Take Silver Survey of Xinhua Village in Yunnan Heqing as an Example [J]. Guizhou Ethnic Studies, 2017(08), p193-197. (in Chinese)

[5] Geng Xiaochen, Study on the Art of Chinese Tin Products [D]. Soochow University, 2013, p76. (in Chinese)

[6] Pan Lusheng, The Revitalization of Traditional Crafts Focuses on Design Innovation [N]. People's Daily, 2018-05-06, Version 1. (in Chinese) 